\title{
Study on the refractive errors of school going children of Pokhara city in Nepal
}

\author{
Niroula DR ${ }^{1}$, Saha CG $^{2}$ \\ ${ }^{1}$ Lecturer, Nobel Medical College \& Teaching Hospital, Biratnagar, Nepal, ${ }^{2}$ Professor and Head, Department of \\ Physiology, Manipal College of Medical Sciences, Pokhara, Nepal
}

\begin{abstract}
Objectives: Refractive errors are the one of the most common visual disorders found worldwide in school going children and it is also one of the causes of blindness. It can easily be prevented, if timely proper measures are taken. In Kathmandu valley and Mechi Zone of Nepal, the distribution of refractive errors was found to be very high. No records are available from the Western part of Nepal. Considering the importance of the refractive errors the present study had been undertaken in Pokhara city.

Materials and methods: Nine hundred and sixty four subjects (474 boys, 490 girls) were selected between age groups 10 to 19 years from six schools representing different region of Pokhara. After Preliminary examination: on acuity of vision with Snellen's and Jaeger's charts, the subjects were referred to the Manipal Teaching Hospital, Pokhara for confirmation of the refractive errors.

Results: Sixty two schools children (6.43\%), out of 964 had refractive errors. Myopia was found to be most common $(4.05 \%)$. The refractive errors were found more in Private school children $(9.29 \%)$ than Government school children (4.23\%), which is statistically significant $(\mathrm{P}<0.05)$. More boys $(7.59 \%)$ were found to have suffered from refractive errors than girls $(5.31 \%)$. Further, children with vegetarian diet $(10.52 \%)$ had greater number of refractive errors than non-vegetarian diet children $(6.17 \%)$.

Conclusion: In the present study, percentage distribution of myopia was found to be higher (4.05\%) than the hyperopia $(1.24 \%)$ and astigmatism (1.14\%). Interestingly, in the present study the refractive errors were found significantly higher in Private schools children than Government schools because the children who read in Private schools have higher socioeconomic status; spend more time in home work, watching Television and Computer as compared to government schools children. These near activities of the eyes causes stress on eyes of the children and might be one of the causes of developing myopia.
\end{abstract}

Key words: Refractive errors, Nepal, Myopia, Hyperopia

$\mathrm{V}$ isual impairment is one of the important health hazards among the school going children ${ }^{1}$. Visual disorders are caused by various physiological, environmental and pathological conditions, and have been reported to be associated with higher rate of morbidity and mortality; in particular, uncorrected refractive errors increase morbidity ${ }^{2}$.

The prevalence of refractive errors of the children varies worldwide. Refractive errors are one of the most common visual impairment in the world ${ }^{3}$. The worldwide study of distribution of refractive errors showed that 800 millions to 2.3 billions people have suffered from refractive errors ${ }^{4}$. Blindness due to refractive errors in any population, suggests that eye care services in that population are inadequate. Since the treatment of refractive errors is perhaps the simplest and effective forms of eye care, it can easily be prevented.
Nepal is a developing country and many people are living under poverty line. One of the most common eye disorders of school going children in Nepal is refractive errors. Many of them are not aware of the eye problems and some of them even do not go for the treatment until vision is badly affected ${ }^{5}$.

There is no nationwide research about the refractive errors in Nepal. Some surveys were done in Kathmandu valley $^{6,7}$ and some in Eastern part at Mechi Zone ${ }^{8}$. So far no studies on refractive errors have been done in Pokhara city, and Western part of Nepal. Considering

Correspondence

Mr. Dilli Ram Niroula

Lecturer

Nobel Medical College \& Teaching Hospital

Biratnagar- 2, Nepal

E-mail: dilliram_manipal@hotmail.com 
the importance of refractive errors, the present survey had been undertaken in Pokhara city.

\section{Material and methods}

In the present study, six secondary schools were selected randomly out of 130 schools keeping in mind that all areas of Pokhara city are represented. The total number of schools children were 964 (474 boys and 490 girls) from grade six to grade ten with age between 10 to 19 years. Among 24,819 numbers of school children in Pokhara'; 1000 school children were randomly selected for Primary examination. But 36 school children were excluded due to incomplete examination. The study had been done from March to June 2006. The Preliminary examination of school children was done at the respective schools. During Primary selection, all subjects were interviewed thoroughly to know their medical history, food habit, economic status etc. Before the examination, the purpose of the study was explained to all the subjects and consent was obtained from the proper authority.

The visual acuity was tested by Snellen's chart for far vision keeping it at six meters distance from the subjects, and near vision was tested with the help of Jaeger's chart keeping the distance of $25-30 \mathrm{~cm}$ from the eyes of the subjects. Other ocular problems were also tested with the help of Torch Light, Ishihara chart etc. The refractive errors were screened; in the schools, by using Pin-hole method. The subjects who had visual acuity equal or less than 6/12 were referred to Manipal Teaching Hospital, Pokhara for further confirmatory examinations. The following examinations were done in Ophthalmology Department: Retinoscopy with Dry and Cycloplegic refraction (Cyclopentolate, 1\%), Ophthalmoscopy and Slit lamp Biomicroscopy. The refractive errors were confirmed with the help of above examinations. Data was analyzed by using SPSS (Statistical Package for Social Science).

The types of refractive errors were separated by following criteria: if refractive error was recorded as "0.5 dioptre" or more spherical power, it was considered as myopia; if refractive error was recorded " +0.5 dioptre" or more spherical power, it was considered as hyperopia (hypermetropia) and if refractive error was found " \pm 0.5 dioptre" or more cylindrical power, it was considered as astigmatism.

\section{Results}

The age of the subjects ranged from 10 years to 19 years with mean age $14.09 \pm 1.65$ years. Among 964 school children 474 (49.2\%) were boys and 490 (50.8\%) were girls from grade six to grade ten.
All the results of the refractive errors observed are summarized in the tables- 1,2,3 and figures-1, 2 .

In table 1 the refractive errors are presented in both sexes. The prevalence of all the varieties of refractive errors was found more in male than female. However, among them myopia seems to be more than hyperopia and astigmatism, but the differences were not statistically significant. In both the sexes' the percentage distribution of myopia was more than other groups.

Table 2 shows the distribution of refractive errors, (all the refractive errors combined) in different age groups from age 10 to 19 years. Very little difference of refractive errors could be observed between different age groups except in the age group of 16 years, where it was slightly more $(8.33 \%)$. In the age groups 10 , $18 \& 19$, the numbers of subjects were very little, so the results are inconclusive. However, the percentage distributions of refractive errors were slightly more in 16 and 17 years.

The prevalence of the refractive errors in private schools was found to be higher $(9.29 \%)$ as compared to the government schools $(4.23 \%)$, which is statistically significant $(\mathrm{P}<0.05)$.

Figure 1 represents the percentage distribution of various types of refractive errors between government and private schools children. When compared among different varieties of refractive errors between private $\&$ government schools, myopia was found to be the most and astigmatism the least.

The refractive errors among different ethnic groups are presented in Table 3. The numbers of the subjects are not equal in all the groups, and the numbers were very low in Newar, Darji, Tamang \& Thakali respectively $(47,33,20$ and 45). The percentage distribution of refractive errors were found to be more in: Brahmin (8.03\%), Chhetri (9.45\%), Newar (8.51\%) and Thakali $(8.89 \%)$.

Out of 964 school students 907 were non-vegetarian and only 57 were vegetarians (Figure 2). Though the difference in numbers were great, we found the percentage distribution of refractive errors was more in vegetarian $(10.52 \%)$ than that in the non-vegetarian $(6.17 \%)$. But the difference was found statistically insignificant. 
Table 1: Distribution of the Refractive Errors of the subjects in two Sexes.

\begin{tabular}{|c|c|c|c|c|c|c|}
\hline Refractive errors & $\begin{array}{c}\text { Boys } \\
(\mathbf{n}=\mathbf{4 7 4})\end{array}$ & $\mathbf{\%}$ & $\begin{array}{c}\text { Girls } \\
(\mathbf{n}=\mathbf{4 9 0})\end{array}$ & $\mathbf{\%}$ & $\begin{array}{c}\text { Total } \\
(\mathbf{n}=\mathbf{9 6 4})\end{array}$ & $\mathbf{\%}$ \\
\hline Myopia & 22 & 4.64 & 17 & 3.47 & 39 & 4.05 \\
\hline Hyperopia & 7 & 1.48 & 5 & 1.02 & 12 & 1.24 \\
\hline Astigmatism & 7 & 1.47 & 4 & 0.81 & 11 & 1.14 \\
\hline Total & 36 & 7.59 & 26 & 5.30 & 62 & 6.43 \\
\hline
\end{tabular}

Table 2: Distribution of the Refractive Errors in different Age group.

\begin{tabular}{|c|c|c|c|}
\hline Age & Total Subjects $(\mathbf{n}=\mathbf{9 6 4 )}$ & $\begin{array}{c}\text { No. of the subjects } \\
\text { with refractive errors }\end{array}$ & $\begin{array}{c}\text { \% } \\
\text { of corresponding age }\end{array}$ \\
\hline 10 & 6 & 0 & 0 \\
\hline 11 & 49 & 3 & 5.12 \\
\hline 12 & 118 & 6 & 6.73 \\
\hline 13 & 193 & 13 & 6.34 \\
\hline 14 & 205 & 13 & 6.04 \\
\hline 15 & 184 & 11 & 8.33 \\
\hline 16 & 144 & 12 & 7.02 \\
\hline 17 & 57 & 4 & 0 \\
\hline 18 & 7 & 0 & 0 \\
\hline 19 & 1 & 0 & \\
\hline
\end{tabular}

Table 3: Distribution of Refractive Errors of the subjects in different Ethnic groups.

\begin{tabular}{|c|c|c|c|}
\hline Ethnic Groups & Total Subjects & $\begin{array}{c}\text { No. of Subjects with } \\
\text { Refractive error }\end{array}$ & \% of corresponding caste \\
\hline Brahmin & 137 & 11 & 8.03 \\
\hline Chhetri & 127 & 12 & 9.45 \\
\hline Magar & 225 & 12 & 5.33 \\
\hline Gurung & 267 & 13 & 8.87 \\
\hline Newar & 47 & 4 & 6.06 \\
\hline Darji & 33 & 2 & 5.00 \\
\hline Tamang & 20 & 1 & 8.89 \\
\hline Thakali & 45 & 4 & \\
\hline
\end{tabular}

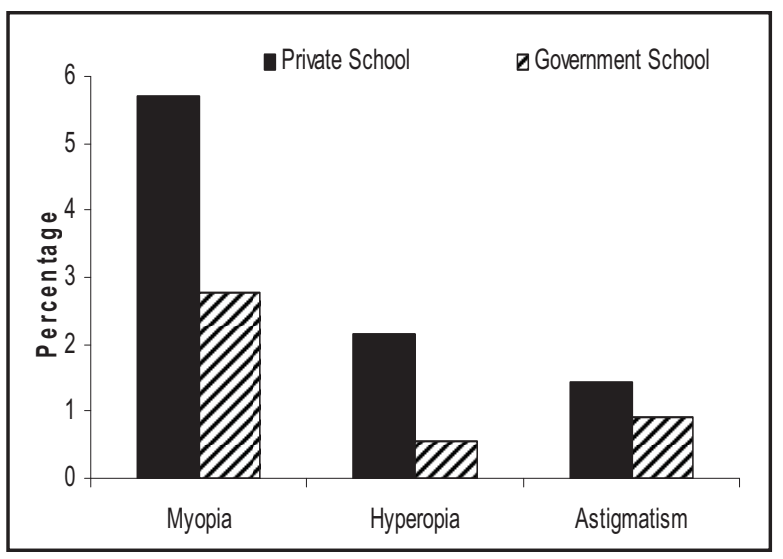

Fig 1: Distribution of refractive errors between Private and government Schools children $(\mathrm{p}<0.05)$.

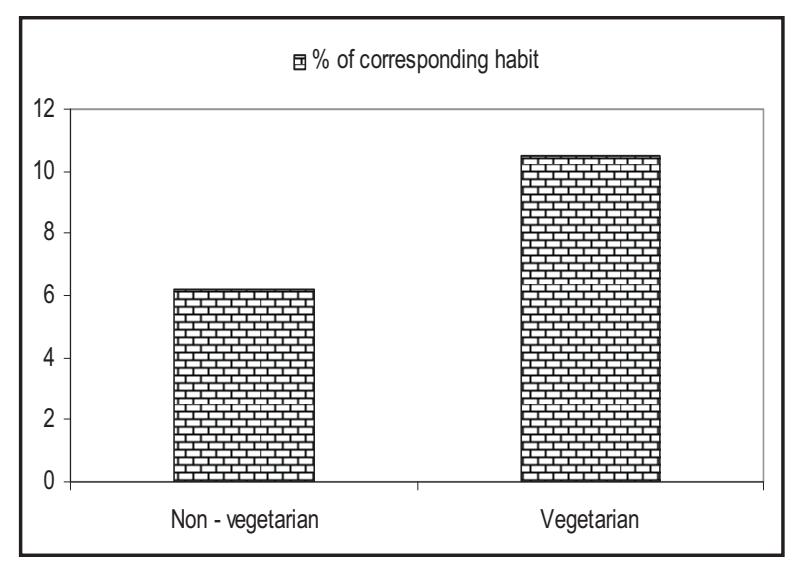

Fig 2: Distribution of Refractive errors between vegetarian and non-vegetarian Subjects ( $p$ values were not statistically significant). 


\section{Discussion}

In our present study, the prevalence of refractive errors among Nine hundred sixty four (964) school going children between 10-19 years old age in Pokhara, Nepal was found to be $6.43 \%$ which is less than the studies of Nepal et $\mathrm{al}^{6}, 8.1 \%$ in $5-17$ years age groups and Shrestha et $\mathrm{al}^{7}$, in 5-16 years of age group children in Kathmandu valley. In another study ${ }^{8}$, out of 5067 children from 5-15 years of age in Mechi, Nepal; only $2.9 \%$ children suffered from the refractive errors. These variations of percentage distribution of refractive errors of different authors are likely to be due to difference in study samples, methodology and definition of refractive errors adopted in their study.

However, the percentage distribution of refractive errors in our present study is higher than the refractive errors recorded by Naidoo et $\mathrm{al}^{\mathbf{1 0}},(4.7 \%)$ in South Africa, and Schimiti et $\mathrm{al}^{11},(4.55 \%)$ in Brazil. On the other hand, the percentage distribution of refractive errors found in India $^{12}$ was $25.32 \%$, in Chile ${ }^{13} 17.05 \%$ and in Zaire ${ }^{14}$ $16 \%$. These studies indicate that the prevalence of refractive errors is much higher than our results. The wide variations of percentage distribution of refractive errors observed by different authors are naturally likely to be due to: sample size, different geographical situation, ethnic variation, nutritional status and different criteria adopted by different authors. It seems that the refractive errors especially in growing children are one of the major health problems in both developed and developing countries.

In our present study, the percentage of refractive errors in the boys is found more $(7.59 \%)$ than in the girl's counterpart $(5.31 \%)$. This result is different from other studies, where the percentage of refractive errors in girls was found higher as compared to boys ${ }^{15,16}$. However, some studies in $\mathrm{Nepal}^{\mathbf{8}}$, Chile ${ }^{13}$ did not found gender difference in refractive errors.

It is interesting to note that in our present study, among the refractive errors, percentage distribution of myopia was found to be higher than that in hyperopia and astigmatism. During the growing period of children (10-19 years age), they are subjected to various stresses and strains on eyes: near vision for reading and writing, watching Television and Computers for more hours etc. Such strains are likely to be the cause of developing myopia $^{\mathbf{1 2}}$. The relationship between near work and myopia had been observed by Saw et al ${ }^{17}$ in Singapore, Mutti et $\mathrm{al}^{18}$ in Orinda \& Colorado and Wong et $\mathrm{al}^{19}$ in Hong Kong. In longitudinal study by Mutti et $\mathrm{al}^{18}$, they showed that heredity is most important factor associated with Juvenile myopia, but the weakness of our study was that parental status of refractive errors were not taken during the study.
The refractive errors in private school children were found higher $(9.29 \%)$ than the government school children $(4.23 \%)$, which is statistically significant. The present study agrees well with other studies done in Nepal. The similar results were observed by shrestha et $\mathrm{al}^{7}$ in Kathmandu Valley. He found in Private school children, 21 percent children had refractive errors whereas Nepal et $\mathrm{al}^{6}$ observed 8.1 percent in Government school children.

The high prevalence of myopia among the refractive errors seems to be associated with increased near works load in the private school children. Children do more homework in private schools as compared to government schools. In the present study socioeconomic status of the children in private schools are comparatively better than government schools. The time spent in Television and Computer is also found more in private schools children, which may be the reasons for development of the refractive errors. This inference is drawn on the basis of direct interview taken on children on their daily habit.

In our present study, Brahmin, Chhetri, Newar and Thakali children showed more refractive errors (Table 3 ). The literacy rate among these ethnic groups is higher as compared to other ethnic groups which also indicate the reason of high refractive errors in them. One study from Kathmandu ${ }^{20}$ also found that the refractive errors were more common in Newar community. Crawford \& $\mathrm{Hammer}^{4}$ also found that the racial and ethnic difference, affects the prevalence of refractive errors.

In the present study, we found that $10.52 \%$ of vegetarian and $6.17 \%$ of non-vegetarian school children had refractive errors. The higher rate is though statistically not significant. The nutritional factor may be one of the important factors in causing the refractive errors in the children.

\section{Conclusion}

In many parts of the world, refractive errors seem to be the second largest cause of treatable blindness after cataract. Blindness due to refractive errors is a substantial public health problem in many parts of the world. Since the treatment of refractive errors is probably the simplest and most effective of eye care interventions ${ }^{3}$, its presence implies inadequate eye care service in the population concerned. Uncorrected refractive errors are not only considered as a serious issue in developing countries but also in developed countries like Australia ${ }^{21}$. So it is desirable to start a worldwide program for elimination of blindness due to refractive errors. 
In the present study, it showed that $6.43 \%$ of schools going children in Pokhara city are suffering from refractive errors. The school going children are the backbone of a Nation. Unless there is a nationwide program for corrective measures of refractive errors, blindness due to unattended refractive errors may cause a great burden on the nation. The percentage distribution of refractive errors found in our studies and studies done by Nepal et al. ${ }^{6}$ and Shrestha et al. ${ }^{7}$ indicate the importance of the problem in Nepal. So the vision screening of school children in developing countries could be very useful in detecting correctable causes of decreased vision especially refractive errors and the corrective measures could be easily taken.

\section{Acknowledgements}

We would like to offer our heartiest thanks to Dr. T.C. Saikia, the Professor and Head, Dr. Soumitra Mukhopadhyay, Professor, Department of Physiology, Nobel Medical College, Biratnagar, Dr. P. S. Debray, and other faculty members of Physiology and Ophthalmology Departments of Manipal College of Medical Sciences, Pokhara. We are also grateful to all the teaching staffs and students of various schools, who helped in data collection and for their participation as subjects in this study.

\section{References}

1. Congdon N, O'colmain B, Klaver CC et al. Eye Diseases Prevalence Research Group- Causes and Prevalence of visual impairment among adults in the United States. Arch. Ophthalmol. 2004;111:1132-40.

2. Fotouhi A, Hashemi H, Raissi B et al. Uncorrected refractive errors and spectacles utilization rate in Tehran: the unmet need. Brit. J. Ophthalmol. 2006;90:534-7.

3. Dandona R, Dandona L. Refractive error blindness. Bull. World Health Organ. 2001;79(3):237-43.

4. Infocus Center for Primary Eye Care Development. Dunway D, Berger I. Worldwide distribution of visual Refractive errors and what to except at a particular location. Presentation to the International Society for Geographic and Epidemiologic Ophthalmology. [cited 2006 Apr 30]. Available from: http://www.infocusonline. org (Acceded on 30 April 2006).

5. National Advisory Eye Council. Vision research: a national plan 1983-1987. United States: United States Department of Health and Human Services, National Institutes of Health Bethesda, MD. (NIH Publication no. 83- 246976): 1983.
6. Nepal BP, Koirala S, Adhikari S et al. Ocular morbidity in School children in Kathmandu. British Journal of Ophthalmology 2003;87:531-4.

7. Shrestha RK, Joshi MR, Pradhan P et al. Ocular morbidity among children studying in Private schools of Kathmandu valley: A prospective cross sectional study. Nepal Medical College Journal 2006;8(1):43-6.

8. Pokharel GP, Negrel AD, Munoz SR et al. Refractive error studies in Children: Results from mechi Zone, Nepal. American Journal of Ophthalmology 2000; 129:436-44.

9. District Education Office. District Education Office Flass Annal Report 2062. Pokhara: District Education Office, Kaski, Nepal: 2063.

10. Naidoo KS, Raghunandan A, Khathutshelo P et al. Refractive error and visual impairment in African children in South Africa. Invest Ophthalmol and Visual Science. 2003;44:376470.

11. Schimiti RB, Costa VP, Gregui MJF et al. Prevalence of Refractive error and Ocular disorders in Preschool and school children of Ibipora- PR, Brazil (1989-1996). Arq. Bras. Oftalmol, 2001;64(5):379-84.

12. Sethi S, Kartha GP. Prevalence of Refractive errors in schools children (12 - 17 years) of Ahmedabad city. Indian J. Com. Med. 2000;25(4):181-3.

13. Maul E, Barroso S, Munoz S et al. Refractive error study in Children: results from La Florida, Chile. American Journal of Ophthalomol 2000;129:445-54.

14. Kaimbo W, Kaimbo D, Missotten L. Ocular RefractioninZaire.Bull-Soc-Belge-Ophthalmol. 1996;261:101-5.

15. Zhao J, Pan X, Sui R et al. Refractive error study in Children: results from Shunyi District, China. American J. Ophthalmol. 2000;129:427-35.

16. Lin LL, Shih YF, Hsiao CK, Chen CJ, Lee LA and Hung PT. Epidemiologic study of the prevalence and severity of myopia among school children in Taiwan in 2000. J. Formos Med. Assoc. 2001;100:684-91.

17. Saw SM, Chua WH, Hong CY, Wu HM, Chan WY, Chia KS et al. Near work in early- onset myopia. Invest Ophthalmol. Vis. Science. 2002a;43:332-9.

18. Mutti DO, Mitchell GL, Moeschberger ML, Jones LA and Zadnik K. Parental myopia, near work, school achievement and children's refractive errors. Invest. Ophthalmol. Vis. Science. 2002;43:3633-40. 
19. Wong L, Coggon D, Cruddas M and Hwang $\mathrm{CH}$. Education reading and familial tendency as risk factors for myopia in Hong Kong fisherman. Journal Epidemol. Community Health. 1993;47:50-3.

20. Karki KJD, Karki M. Refracive error profile- a clinical study. Kathmandu university medical journal. 2003;2(3):208-12.
21. Taylor HR, Livingston PM, Stanislavsky YL et al. Visual Impairment in Australia: distance visual acuity, near vision and Visual Field finding of the Melborne-Vision impairment unit. Amj J. Ophthalmol. 1997;123:328-37. 